\title{
Estrutura de Capital e Mecanismos de Governança Externos à Firma: Uma Análise Multipaís
}

\section{Capital Structure and Governance Mechanisms External to the Firm: A Cross-Country Analysis}

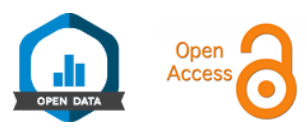

Flávia F. P. Mendonça ${ }^{1}$ (D) Henrique Castro Martins ${ }^{2}$

(1) Paulo R. S. Terra ${ }^{1}$

Fundação Getulio Vargas, Escola de Administração de Empresas de São Paulo, São Paulo, SP, Brasil ${ }^{1}$

Pontifícia Universidade Católica do Rio de Janeiro, Rio de Janeiro, RJ, Brasil ${ }^{2}$

Editora convidada para este artigo: Josete Florêncio dos Santos

Editor-chefe: Wesley Mendes-Da-Silva (iD

\# de revisores convidados até a decisão
Artigo recebido em 03.05.2019

Última versão recebida em 26.09.2019

Aprovado em 27.09.2019

\begin{tabular}{|c|c|c|c|c|c|c|c|c|}
\hline & 1 & 2 & 3 & 4 & 5 & 6 & 7 & 8 \\
\hline $1^{\mathrm{a}}$ rodada & $\otimes$ & $\otimes$ & $\otimes$ & $\otimes$ & $\otimes$ & $\stackrel{9}{2}$ & $\otimes$ & $\stackrel{8}{2}$ \\
\hline $2^{\mathrm{a}}$ rodada & $\stackrel{9}{2}$ & & & & & & & \\
\hline
\end{tabular}




\title{
Resumo
}

Esse estudo investiga em que medida os mecanismos de governança externos à firma afetam a alavancagem de uma amostra de 7.490 empresas de 40 países. O diferencial do estudo está na distinção entre os mecanismos que afetam a proteção dos acionistas minoritários daqueles que afetam os direitos dos credores. Os resultados sugerem que as empresas se alavancam de maneira coerente ao previsto pela Teoria da Pecking Order (POT). Observou-se que os mecanismos associados à proteção de ambas classes de investidores (i.e., acionistas e credores) influenciam significativamente a estrutura de capital das empresas. Quando a proteção é alta, as empresas tomam menos dívida. Os resultados mostraram-se robustos a diversas variações no modelo estudado e indicam que, quando a proteção aos investidores externos é maior, as firmas tomam menos dívida, possivelmente com a finalidade de restringir o papel monitorador da dívida sobre a discricionariedade dos insiders.

Palavras-chave: alavancagem financeira, proteção aos acionistas, direitos dos credores, mecanismos externos de governança.

\begin{abstract}
This study investigates whether governance mechanisms external to the firm affect leverage using a sample of 7.490 companies from 40 countries. Our contribution is to separate mechanisms that protect minority shareholders from those that protect creditors rights. Our results show that companies issue debt following the Pecking Order Theory (POT). We find that both mechanisms protecting shareholders and creditors affect corporate leverage. When protection is high, companies issue less debt. Our results are robust to several alternative specifications and variations in our model. We interpret our results as evidence that, when investors are well protected, firms issue less debt, possibly to avoid the monitoring role of debt over the discretion of insiders.
\end{abstract}

Keywords: leverage, shareholders protection, creditors rights, external governance mechanisms.

JEL Code: G3, O57, P33. 


\section{Introdução}

A profícua literatura de Law and Finance (La Porta, Lopez-de-Silanes, Shleifer, \& Vishny, 1998) propõe que o desenvolvimento e estrutura dos mercados de capitais, bem como as decisões de investidores e empresas, dependem em alguma medida das instituições que garantam seus direitos e viabilizem o cumprimento de contratos. Contudo, a maior parte dessa literatura trata a proteção aos investidores como homogênea dentro de cada país. Neste trabalho, propõe-se expandir e refinar essa literatura ao separar instituições que protegem os direitos dos credores de instituições que garantem a proteção aos acionistas minoritários sobre a estrutura de capital das empresas. Dessa forma, o trabalho contribui para a literatura que estuda a relação entre instituições nacionais e a alavancagem corporativa.

A teoria da irrelevância da estrutura de capital de Modigliani e Miller (1958) sugere que, em um mercado perfeito, o valor da firma independe da sua alavancagem e não existe um nível ótimo de endividamento. No entanto, diversos estudos indicam que estrutura de capital altera o valor da firma através da presença potencial de conflitos de agência, assimetria de informação, custos de transação e custos de falência (Jensen \& Meckling, 1976; Modigliani \& Miller, 1963; Myers \& Majluf, 1984).

Dentre esses estudos, Wald (1999), por exemplo, indica que a estrutura de capital é afetada por problemas de agência, pois ela origina potenciais conflitos de interesse entre executivos, acionistas e credores. Mesmo dentro do grupo dos acionistas, existem potenciais conflitos de interesse entre os acionistas minoritários e acionistas majoritários (Young, Peng, Ahstrom, Bruton, \& Jiang, 2008). Além disso, diversos estudos (e.g., Denis \& McConnell, 2003; La Porta, Lopez-de-Silanes, Shleifer, \& Vishny, 2000) indicam que os mecanismos de governança corporativa e de proteção aos investidores, tanto no nível da empresa quando no nível do país, são cruciais para conter a potencial expropriação da riqueza dos outsiders (i.e. acionistas minoritários e credores) pelos insiders (i.e. acionistas majoritários e executivos).

Grande parte da diferença entre os sistemas de governança dos países se dá devido à diferença na natureza das obrigações legais que os executivos têm com os investidores e, também, na diferença com que o sistema jurídico interpreta e faz cumprir (i.e., enforcement) essas obrigações (La Porta et al., 2000). Para La Porta, Lopezde-Silanes, Shleifer e Vishny (1998), a maneira na qual os contratos podem ser utilizados para mitigar esses problemas de incentivo dependem do sistema legal, que consiste no conteúdo das leis e na qualidade do seu enforcement. Consequentemente, Fan, Titman e Twite (2012) argumentam que os meios (ou mecanismos) pelos quais os países resolvem os potenciais conflitos de interesse entre insiders e outsiders são determinantes importantes para as políticas financeiras das empresas, como, por exemplo, a alavancagem. Booth, Aivazian, Demirgüç-Kunt e Maksimovic (2001) e Bancel e Mittoo (2004), inclusive, argumentam que as diferenças institucionais são tão importantes quanto as características da empresa na determinação do nível de endividamento.

Com base nessa literatura, este trabalho investiga como o nível de proteção aos investidores afeta decisões de alavancagem. Particularmente importante, faz-se a distinção entre mecanismos de governança externos à firma (por conveniência os denominamos de Mecanismos Externos de Governança ou simplesmente MEG) que garantem proteção aos acionistas daqueles que garantem os direitos dos credores. Assim, esse trabalho busca responder a seguinte questão de pesquisa: como os MEG relacionados à proteção dos acionistas e relacionados aos direitos dos credores afetam a escolha da alavancagem corporativa?

Este trabalho possui o objetivo principal de examinar qual a relação entre a proteção dos investidores, no nível país, e a escolha pela estrutura de capital ao nível da empresa. Foca-se nas decisões de alavancagem pelo fato de que essas decisões, além de serem fundamentais para a estratégia financeira da empresa, sinalizam as preferências dos acionistas em relação ao risco financeiro assumido (Acharya, Amihud, \& Litov, 2011), ao mesmo tempo em que dependem do desenvolvimento financeiro proporcionado pela proteção aos direitos dos credores (Djankov, McLiesh, \& Shleifer, 2007). Isto posto, o presente trabalho faz uma análise multipaís e estuda as decisões de alavancagem de 7.490 empresas distribuídas em 40 países entre os anos 2005 e 2014. 
Este trabalho possui semelhanças com Cheng e Shiu (2007) e Jong, Kabir e Nguyen (2008), mas com uma importante contribuição. Em contraponto aos trabalhos anteriores, que consideram a proteção do investidor unidimensional, o presente trabalho distingue os MEG que atuam sobre os direitos do credor daqueles que agem sobre a proteção dos acionistas. Consistentemente com estudos prévios sobre alavancagem financeira (e.g., Booth, Aivazian, Demirgüç-Kunt, \& Maksimovic, 2001; Cheng \& Shiu, 2007; Fan, Titman, \& Twite, 2012; Jong, Kabir, \& Nguyen, 2008; Rajan \& Zingales, 1995), esta pesquisa analisa o efeito conjunto entre (a) características no nível da firma e (b) os MEG no nível país na decisão de estrutura de capital da firma. Neste trabalho, distinguem-se os MEG que garantem proteção aos acionistas minoritários daqueles que protegem os direitos dos credores. Essa distinção é importante para capturar mais apropriadamente as diferenças entre os países acerca das decisões de alavancagem dentro de um contexto de potencial informação assimétrica entre acionistas, credores e executivos. Nossa asserção é que a alavancagem da empresa é influenciada pelos MEG que facilitam o monitoramento externo e o cumprimento dos contratos financeiros, ou seja, a alavancagem corporativa depende da combinação entre o nível de proteção dos acionistas e dos direitos dos credores de cada país.

\section{Referencial Teórico}

A estrutura de capital corporativa se refere à maneira pela qual a empresa se financia através de capital próprio (acionistas) e de capital de terceiros (credores). Dentre as principais teorias que versam sobre essas decisões, destacam-se as Teorias de Agência, Market Timing, Trade-off Estático e Pecking Order. Em cada uma dessas teorias, a escolha entre capital próprio e capital de terceiros depende tanto de fatores específicos da empresa quanto de fatores institucionais (Booth et al., 2001). Os fatores em nível de firma e em nível institucional que influenciam as empresas na sua decisão sobre a estrutura de capital têm sido motivo de debate há décadas entre os acadêmicos (e.g., Booth et al., 2001; Fan et al., 2012; Frank \& Goyal, 2003; Jong et al., 2008; Rajan \& Zingales, 1995; Shyam-Sunder \& Myers, 1999).

Dentre os fatores institucionais, a proteção ao investidor é, talvez, o principal determinante da estrutura de propriedade das empresas (Cheng \& Shiu, 2007; Jong et al., 2008). Para La Porta, Lopez-de-Silanes, Shleifer e Vishny (2000), a diferença na estrutura de capital entre países se dá em função do quão bem protegidos pela legislação são os investidores (tanto acionista minoritário quanto credor) de expropriação pelos insiders. Para os autores, a abordagem jurídica é melhor para entender a governança corporativa do que a tradicional distinção entre mercados bank-based e market-based. Segundo La Porta et al. (2000), além da relação com estrutura de propriedade, a proteção dos investidores estimula o desenvolvimento dos mercados financeiros. Isto é, à medida que os investidores são melhores protegidos de expropriação pelos insiders, eles dispõem-se a pagar um prêmio pelos títulos da firma, reduzindo o seu custo de capital. Isso torna atraente para a empresa emitir títulos financeiros ao mercado.

Em países de baixa proteção aos acionistas, no entanto, a atratividade em captar recursos via emissão de títulos a investidores externos diminui, o que aumenta a probabilidade de a estrutura de propriedade acionária das empresas ser concentrada. Consequentemente, surge um conflito de agência nas empresas com alta concentração acionária entre os acionistas minoritários e os sócios controladores (Young et al., 2008), que, de acordo com a literatura anterior, poderia ser mitigado pelo aumento da proteção legal dos direitos dos acionistas (La Porta et al., 1998). Adicionalmente, em países com menor proteção aos investidores, os mercados financeiros tendem a ser menores e menos desenvolvidos (Djankov et al., 2007). Por isso, qualquer análise comparativa de governança deve controlar o efeito de governança no nível país.

Grande parte da diferença entre os sistemas de proteção legal dos países se dá pela diferença (a) na natureza da obrigação legal que os executivos têm junto aos investidores externos e (b) na maneira pela qual a justiça interpreta e faz cumprir essas obrigações (Shleifer \& Vishny, 1997). La Porta et al. (2000) identificam que tanto a extensão legal quanto a proteção sobre os direitos de votos dos acionistas variam muito entre os países.

Além disso, a literatura sugere que os mecanismos de governança no nível país melhoram a transparência das informações e mitigam os conflitos de agência (Schiehll \& Martins, 2016). A fim de garantir financiamento 
de acionistas minoritários e credores, a firma precisa se comprometer, por meio de contratos legais, a mitigar os comportamentos oportunistas dos seus executivos e dos acionistas majoritários. A efetividade desses contratos depende tanto das características da firma quanto dos mecanismos de governança externos à firma, que facilitam o monitoramento externo e o cumprimento da lei. De acordo com essa literatura, pode-se dizer que os MEG são tudo aquilo que não é inerente à empresa, mas é inerente à proteção dos investidores por meios externos à firma. Em outras palavras, são instituições formais, no nível país, tais como leis e regulações, jurisprudência, regras econômicas e políticas, códigos de condutas e valores, dentre outros.

Por exemplo, maiores níveis de proteção ao credor proporcionam-lhe maior poder em situações de liquidação ou falência (Djankov, Hart, McLiesh, \& Shleifer, 2008). Com isso, eles possuem maior poder para forçar o pagamento da dívida, para receber os ativos que foram usados como colaterais e para assumir o controle da empresa em caso de falência. Isso tudo diminui o risco do crédito, de modo que o credor irá demandar juros menores sobre a dívida. No entanto, não há garantias de que a diminuição do risco de crédito acarrete proteção dos acionistas minoritários. De acordo com Martins, Schiehll e Terra (2015), por exemplo, alguns países possuem conflitos de agência relacionados à concentração de propriedade devido à fraca proteção dos acionistas minoritários e, ao mesmo tempo, possuem baixos custos de agência associados à forte proteção aos direitos dos credores.

Empiricamente, em um estudo para explicar a variação da alavancagem utilizando uma amostra de empresas de nove países do Leste Europeu, Jõeveer (2013) encontra que cerca de metade da variação da alavancagem relacionada a fatores específicos do país é explicada por fatores macroeconômicos e institucionais conhecidos, enquanto o restante é explicado pelas diferenças institucionais não mensuráveis, como leis e cumprimento das leis. Por sua vez, Jong et al. (2008) encontram que os determinantes específicos da alavancagem no nível da firma variam entre países. Além disso, fatores específicos de país também influenciam nos papéis dos fatores específicos da empresa na escolha da estrutura de capital. La Porta et al. (2000), por sua vez, documentam que empresas em países com alta proteção aos acionistas possuem baixa concentração acionária e melhor acesso ao financiamento externo do que comparado com países com baixa proteção ao acionista. Podem-se citar ainda os resultados de Demirgüç-Kunt e Maksimovic (1999) que estudam 30 países desenvolvidos e emergentes e encontraram que diferenças institucionais entre esses países explicam a variação no uso de dívidas de longo prazo, e de Bancel e Mittoo (2004) que encontram que a política de financiamento das empresas é influenciada tanto pelo seu ambiente institucional quanto pelas suas operações internacionais.

Apesar da variação dos determinantes do grau de alavancagem já ter sido amplamente estudada entre países (e.g., Booth et al., 2001; Demirgüç-Kunt \& Maksimovic, 1999; Fan et al., 2012; Rajan \& Zingales, 1995; Wald, 1999), essa literatura não faz a distinção entre os fatores de governança no nível país separando a proteção aos acionistas minoritários dos direitos dos credores. Dentre esses estudos, parece não haver consenso sobre diferenças sistemáticas na forma como as decisões de endividamento são afetadas por fatores específicos de país. Por exemplo, Fan et al. (2012) encontram um impacto significativo da origem do sistema legal e dos códigos de falência e sistema de impostos do país na estrutura de capital. Booth et al. (2001) estudam 10 países em desenvolvimento com intuito de verificar se as variáveis que afetam a estrutura de capital seriam as mesmas de países desenvolvidos. Eles encontram que existem diferenças específicas entre países que afetam a alavancagem tais como diferenças nos impostos, proteção aos investidores e ambientes institucionais. Já Cheng e Shiu (2007) analisam o papel das características da firma e as diferenças institucionais na estrutura de capital de 45 países, focando nas diferenças entre a proteção dos investidores nos países, utilizando como proxy para a proteção dos investidores os índices anti-director e creditor rights scores desenvolvidos em La Porta et al. (1998). Apesar disso, eles não analisam as situações em que os países apresentam desequilíbrio entre os níveis de proteção ao acionista e de proteção aos credores.

Até onde tem-se conhecimento, Cheng e Shiu (2007) e Jong et al. (2008) são os únicos que estudam a alavancagem corporativa associada a fatores institucionais de proteção aos investidores. Esses autores incorporam variáveis específicas de país, entre elas os índices de proteção ao credor e acionista definidos por La Porta et al. (1998), mas não controlam para a sobreposição entre os níveis de proteção dos dois tipos de investidores. 


\section{Hipóteses}

O entendimento convencional da literatura sugere que maior proteção aos investidores é um canal condutor para o desenvolvimento do mercado de capitais e ao crescimento e desenvolvimento econômicos (La Porta et al., 1998, 2000). Portanto, à medida que os MEG melhoram, mais capital estaria disponível para as empresas utilizarem em termos de dívida e capital próprio. Contudo, essa literatura não distingue efeitos sobre os credores de efeitos sobre acionistas minoritários, apesar das instituições nacionais não os protegerem de forma equilibrada ou homogênea: alguns países privilegiam um grupo mais do que outro. Dessa forma, a literatura não é capaz de oferecer predições inequívocas sobre a relação entre dívida e capital próprio das empresas. Em contrapartida, a separação desses dois grupos de investidores outsiders, permite a elaboração de predições quanto à estrutura de capital das empresas.

A literatura existente sugere que a assimetria de informação entre outsiders e insiders gera incerteza sobre o retorno para os investidores externos e isso influencia diretamente as escolhas das empresas entre capital próprio e capital de terceiros (Myers \& Majluf, 1984). As instituições nacionais de proteção aos investidores, que permitem maior monitoramento e cumprimento dos contratos financeiros, são capazes de mitigar a assimetria de informação entre os agentes da economia. Consequentemente, a qualidade institucional diminui as fricções nos mercados de forma que investidores outsiders (acionistas minoritários e credores) são mais propensos a ceder capital para a firma, uma vez que existe maior proteção aos seus direitos (Djankov et al., 2007; Djankov, La Porta, Lopez-deSilanez, \& Shleifer, 2008). Em países com alta proteção ao credor, Djankov, McLiesh e Shleifer (2007) documentam que o mercado de crédito cresce, o que aumenta a oferta de capital de terceiros na economia e aumenta o desenvolvimento financeiro dos países. Já Cheng e Shiu (2007) sugerem que as firmas em países com alta proteção aos acionistas deveriam contrair menos dívida, relativamente a firmas de países com menor proteção.

Portanto, um aprimoramento nos MEG tornaria o crédito e o capital próprio mais abundantes e, consequentemente, mais baratos, reduzindo o custo de capital para as empresas. Sob a perspectiva da Teoria da Pecking Order [POT] (Myers \& Majluf, 1984), as empresas escolheriam a fonte de capital que oferecesse os menores custos de agência. De acordo com a teoria, existe uma hierarquia no uso de fontes de capital: a empresa daria preferência ao financiamento interno e, caso necessite de financiamento externo, a sequência seria a emissão de dívidas e, por fim, emissão de ações. Logo, a estrutura de capital dependeria de qual grupo de investidores outsiders seria relativamente melhor protegido (credores ou acionistas minoritários), posto que os custos de agência decorreriam da qualidade dos MEG. Esse argumento conduz às seguintes hipóteses:

$\mathbf{H}_{1 \mathbf{a}}$ : a maior proteção aos credores está positivamente relacionada com a alavancagem.

$\mathbf{H}_{\mathbf{1 b}}$ : a maior proteção aos acionistas está negativamente relacionada com a alavancagem.

Por outro lado, Acharya, Amihud e Litov (2011) demonstram que, como forma de se proteger da tomada de controle por agentes externos, os agentes internos (executivos e/ou acionistas majoritários) se tornam mais avessos ao risco quando a proteção legal dos credores aumenta. Nessas situações, eles procurariam evitar o ônus do monitoramento externo, recorrendo mais intensamente aos recursos gerados internamente pela empresa. Isso leva à intuição que maior proteção aos investidores externos levaria a empresa a recorrer menos a recursos externos. Se o efeito inibidor do monitoramento impuser custos muito altos aos agentes internos, esses podem optar por utilizar menos capital de terceiros à medida que a proteção aos credores aumenta. Um raciocínio similar para o caso da proteção aos acionistas minoritários levaria a uma maior utilização de dívida. A alavancagem da empresa, mais uma vez, dependeria do custo relativo entre as duas fontes de recursos, nos moldes da POT. Isso leva às seguintes hipóteses:

$\mathbf{H}_{\mathbf{2 a}}$ : a maior proteção aos credores está negativamente relacionada com a alavancagem.

$\mathbf{H}_{\mathbf{2 b}}$ : a maior proteção aos acionistas está positivamente relacionada com a alavancagem.

Observa-se que os conjuntos de hipóteses $\mathrm{H}_{1}$ e $\mathrm{H}_{2}$ são concorrentes. Qual dessas hipóteses prevalecerá é a questão empírica que esse trabalho busca responder. 


\section{Método}

\section{Descrição da amostra}

A seleção inicial da amostra foi composta pelos 49 países que estão incluídos em La Porta et al. (1998). Essa escolha deu-se pelo fato de o trabalho desses autores incluir informações no nível país sobre a proteção dos credores e acionistas. Em seguida, fez-se o levantamento de dados de todas as empresas listadas publicamente, entre os anos de 2005 e 2014, listadas no Bureau Van Dijk ORBIS, com base no ano fiscal de 2014. Os dados utilizados são provenientes dos demonstrativos financeiros da empresa, com observações anuais. As informações no nível macroeconômico foram retiradas do site do Banco Mundial (taxa de inflação e PIB per capita) e do site Trading Economics (Alíquota do Imposto de Renda Empresarial, https://tradingeconomics.com/countrylist/corporate-tax-rate).

Em conformidade com Almeida e Campello (2007), excluiu-se da amostra empresas: (a) financeiras; (b) com Patrimônio Líquido negativo; (c) com Capital Social menor do que US\$ 5 milhões; (d) com crescimento de ativos totais e de receita bruta de vendas maior que $100 \%$ ou menor que $-100 \%$ de um ano para o outro; (e) com Q de Tobin negativo ou maior do que 10; e (f) que não possuíam um mínimo de três anos consecutivos de informações. Os resultados reportados neste estudo são os obtidos após essas exclusões, porém os achados são robustos quando não se exclui essas empresas (resultados omitidos, mas disponíveis mediante solicitação aos autores).

Em função desses critérios, foram excluídas todas as empresas de Chile, Uruguai e Venezuela. Devido à falta de informações sobre a proteção do credor, as empresas de mais seis países foram eliminadas da amostra: Índia, Quênia, Nigéria, Paquistão, Taiwan e Zimbabwe. A amostra final é composta pelos 40 países restantes e engloba um total de 7.490 empresas e 59.588 observações. Para o tratamento de outliers, optou-se pela winsorização de $1 \%$ de cada extremo da distribuição da variável dependente e das variáveis independentes ROA, Oportunidades de crescimento e Tangibilidade (vide descrição das variáveis a seguir).

\section{Definição de variáveis}

A variável dependente é o grau de alavancagem financeira medido da seguinte maneira:

$$
\text { Alavancagem }_{i t}=\frac{\text { Dívida Total }_{\text {it }}}{\text { Ativos Totais }_{i t}}=\frac{\text { Dívida de Curto Prazo } i t+\text { Dívida de Longo Prazo }}{\text { it }}
$$

Baseando-se na literatura sobre estrutura de capital (e.g., Booth et al., 2001; Cheng \& Shiu, 2007; Fan et al., 2012; Jong et al., 2008; Rajan \& Zingales, 1995), seleciona-se seis características das empresas que estão correlacionadas com alavancagem: oportunidades de crescimento, tamanho da empresa, lucratividade, incerteza do negócio, tangibilidade dos ativos e setor de atividade. Ainda, adiciona-se dummies setoriais, utilizando-se a classificação de 30 indústrias de Fama e French (1997). Além disso, inclui-se variáveis em nível de país seguindo Cheng e Shiu (2007), Demirgüç-Kunt e Maksimovic (1999), e Fan et al. (2012), a saber: crescimento do Produto Interno Bruto (PIB), taxa anual de inflação, alíquota do imposto de renda empresarial, tratamento tributário de prejuízos (loss carryback), bem como os indicadores de proteção ao credor e ao acionista que são definidos adiante.

A Tabela 1 sumariza as variáveis utilizadas, e a Tabela 2 contém os coeficientes de correlação entre todas as variáveis. Pode-se notar o alto desvio padrão de algumas variáveis, sugerindo elevada heterogeneidade na amostra. Observa-se também que a média de alavancagem é próxima de 41,3\%. Além disso, a correlação entre as variáveis é geralmente baixa, de forma que problemas de multicolinearidade não deverão estar presentes nas estimações. Em termos de representatividade, cerca de 17,50\% das empresas são do Japão e 13,76\% são da Coreia de Sul. A Turquia foi o país menos representado, com apenas 0,05\% do total (valores omitidos, mas disponíveis mediante solicitação). 
Tabela 1

\section{Estatística Descritiva das Variáveis e Proxy Utilizada}

\begin{tabular}{|c|c|c|c|c|c|c|c|}
\hline Variável & Proxy & Min. & Média & Med. & Máx. & D.P. & Obs. \\
\hline Alavancagem & 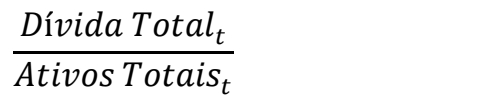 & 0,040 & 0,413 & 0,418 & 0,829 & 0,185 & 59588 \\
\hline $\begin{array}{l}\text { Oportunidade de } \\
\text { Crescimento }\end{array}$ & $\frac{\text { Mkt Cap }}{\text { Shareholders Equity }_{t}}$ & 0,205 & 1,623 & 1,214 & 6,920 & 1,298 & 59588 \\
\hline Tamanho & $\log \left(\right.$ vendas $\left._{t}\right)$ & 8,403 & 19,603 & 19,422 & 27,038 & 1,943 & 59588 \\
\hline Lucratividade & $R O A=\frac{\text { LAIR }_{t}}{{\text { Ativos } \text { Totais }_{t}}^{\text {ativat }}}$ & $-0,299$ & 0,057 & 0,055 & 0,322 & 0,088 & 59588 \\
\hline Incerteza do Negócio & $\sqrt{\frac{\sum_{t=1}^{N}\left(R O A_{i t}-\overline{R O A_{l}}\right)^{2}}{N-1}}$ & 0,000 & 0,053 & 0,043 & 0,273 & 0,037 & 59588 \\
\hline Tangibilidade & $\frac{\text { Ativos Permanentes }_{t}}{{\text { Ativos } \text { Totais }_{t}}}$ & 0,005 & 0,303 & 0,271 & 0,892 & 0,218 & 59588 \\
\hline Loss Carryback & $\begin{array}{l}\text { Dummy igual a } 1 \text { se o país } \\
\text { permite o Loss Carryback }\end{array}$ & 0,000 & 0,236 & 0,000 & 1,000 & 0,424 & 59588 \\
\hline Alíquota IR Empresarial & Alíquota do IR Empresarial & 0,125 & 0,301 & 0,296 & 0,407 & 0,070 & 59588 \\
\hline Crescimento PIB & Crescimento anual do PIB do país & $-9,132$ & 2,281 & 2,292 & 15,240 & 2,953 & 59588 \\
\hline Inflação & Inflação anual do país & $-0,060$ & 0,020 & 0,016 & 0,293 & 0,033 & 59588 \\
\hline
\end{tabular}

Nota. Estatísticas descritivas das variáveis utilizadas no modelo, bem como a proxy utilizada. 


\section{Tabela 2}

\section{Tabela de Correlação}

\begin{tabular}{|c|c|c|c|c|c|c|c|c|c|c|c|c|c|}
\hline & & 1 & 2 & 3 & 4 & 5 & 6 & 7 & 8 & 9 & 10 & 11 & 12 \\
\hline 1 & Alavancagem & 1 & & & & & & & & & & & \\
\hline 2 & Oportunidades de Crescimento & 0,074 & 1 & & & & & & & & & & \\
\hline 3 & Tamanho & 0,316 & 0,098 & 1 & & & & & & & & & \\
\hline 4 & Lucratividade & $-0,222$ & 0,326 & 0,128 & 1 & & & & & & & & \\
\hline 5 & Incerteza do negócio & $-0,146$ & 0,093 & $-0,269$ & $-0,146$ & 1 & & & & & & & \\
\hline 6 & Tangibilidade & $-0,014$ & $-0,102$ & 0,027 & $-0,066$ & $-0,054$ & 1 & & & & & & \\
\hline 7 & Loss Carryback & $-0,062$ & 0,164 & 0,103 & $-0,003$ & 0,150 & $-0,005$ & 1 & & & & & \\
\hline 8 & IR Empresarial & 0,017 & $-0,007$ & 0,191 & $-0,005$ & $-0,108$ & $-0,039$ & 0,121 & 1 & & & & \\
\hline 9 & Crescimento PIB & $-0,070$ & 0,057 & $-0,155$ & 0,112 & 0,051 & 0,064 & $-0,160$ & $-0,316$ & 1 & & & \\
\hline 10 & Inflação & $-0,022$ & 0,074 & $-0,135$ & 0,106 & 0,071 & 0,115 & $-0,015$ & $-0,206$ & 0,333 & 1 & & \\
\hline 11 & Proteção aos acionistas minoritários & $-0,130$ & $-0,034$ & $-0,071$ & $-0,005$ & 0,104 & 0,040 & 0,147 & $-0,060$ & 0,186 & $-0,121$ & 1 & \\
\hline 12 & Direito dos credores & $-0,033$ & $-0,142$ & 0,006 & $-0,073$ & $-0,062$ & $-0,013$ & $-0,130$ & $-0,053$ & $-0,012$ & $-0,395$ & 0,311 & 1 \\
\hline
\end{tabular}

Nota. Coeficientes de correlação entre todas as variáveis utilizadas no modelo. 


\section{Cálculo dos indicadores de proteção aos investidores}

Para considerar as diferenças entre a proteção dos investidores, seguindo Martins et al. (2015), foram criados dois indicadores: um de proteção ao direito dos credores e outro de proteção aos acionistas minoritários. Para compor esses indicadores, utiliza-se índices disponíveis na literatura ${ }^{(1)}$. Os indicadores calculados são a soma de cinco índices seminais diferentes. Alguns desses índices seminais foram ajustados para que variassem entre 0 e 1 , de forma que os dois indicadores calculados ficassem entre 0 e 5 . A descrição de cada índice utilizado bem como os autores que os desenvolveram está na Tabela 3. A correlação do tipo pairwise entre os dois indicadores é de aproximadamente 0,3197 , o que sugere que os indicadores de proteção aos investidores medem fatores distintos na governança no nível país.

Tabela 3

\section{Índices Utilizados para Compor os Indicadores}

\begin{tabular}{|c|c|c|c|}
\hline & Índices & Descrição & Fonte do Indicador \\
\hline \multirow{5}{*}{ 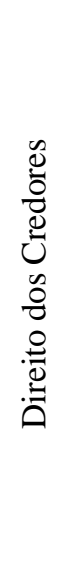 } & Reserva Legal & $\begin{array}{l}\text { Quanto maior a reserva legal, mais protegidos estão os } \\
\text { credores. Esse índice varia entre } 0 \text { e } 1 \text {. }\end{array}$ & La Porta et al. (1998) \\
\hline & $\begin{array}{l}\text { Cumprimento de } \\
\text { contrato }\end{array}$ & $\begin{array}{l}\text { Quantidade de dias necessária para resolver um problema de } \\
\text { insolvência na justiça. Utilizou-se } 1 / \ln \text { (\#dias) e alterou-se o } \\
\text { índice para que varie entre } 0 \text { e } 1 \text {. }\end{array}$ & $\begin{array}{l}\text { Djankov, La Porta, } \\
\text { Lopez-de-Silanes e } \\
\text { Shleifer (2003) }\end{array}$ \\
\hline & Direito dos Credores & $\begin{array}{l}\text { Índice que agrega diferentes direitos dos credores. } O \text { índice } \\
\text { original varia entre } 0 \text { e } 5 \text {, porém alterou-se de forma que varie } \\
\text { entre } 0 \text { e } 1 \text {. }\end{array}$ & Djankov et al. (2007) \\
\hline & $\begin{array}{l}\text { Compartilhamento de } \\
\text { Informações }\end{array}$ & $\begin{array}{l}\text { Igual a } 1 \text { se um public registry ou private bureau opera no } \\
\text { país e } 0 \text { caso contrário. }\end{array}$ & Djankov et al. (2007) \\
\hline & $\begin{array}{l}\text { Cumprimento do } \\
\text { Débito }\end{array}$ & $\begin{array}{l}\text { Valor estimado de recuperação de dívidas através de } \\
\text { mecanismos legais. Varia entre } 0 \text { e } 1 .\end{array}$ & $\begin{array}{l}\text { Djankov, Hart, McLiesh, } \\
\text { e Shleifer (2008) }\end{array}$ \\
\hline \multirow{5}{*}{ 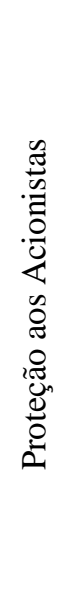 } & $\begin{array}{l}\text { Dividendos } \\
\text { Obrigatórios }\end{array}$ & $\begin{array}{l}\text { Porcentagem do Lucro Líquido que a empresa deve distribuir } \\
\text { via dividendos. Varia entre } 0 \text { e } 1 \text {. }\end{array}$ & La Porta et al. (1998) \\
\hline & $\begin{array}{l}\text { Requerimentos de } \\
\text { Disclosure }\end{array}$ & $\begin{array}{l}\text { Nível de disclosure obrigatório sobre as atividades da } \\
\text { empresa. Varia entre } 0 \text { e } 1 \text {. }\end{array}$ & $\begin{array}{l}\text { La Porta, Lopez-de- } \\
\text { Silanes e Shleifer (2006) }\end{array}$ \\
\hline & $\begin{array}{l}\text { Padrão de } \\
\text { Responsabilidade }\end{array}$ & $\begin{array}{l}\text { Mede a qualidade da regulação do processo de emissão de } \\
\text { novas ações. Varia entre } 0 \text { e } 1 \text {. }\end{array}$ & La Porta et al. (2006) \\
\hline & Anti-self-dealing & $\begin{array}{l}\text { Suporte à proteção ao acionista minoritário contra o self- } \\
\text { dealing do acionista controlador. Varia entre } 0 \text { e } 1 \text {. }\end{array}$ & $\begin{array}{l}\text { Djankov, La Porta, } \\
\text { Lopez-de-Silanez e } \\
\text { Shleifer (2008) }\end{array}$ \\
\hline & $\begin{array}{l}\text { Índice de direitos anti- } \\
\text { directors }\end{array}$ & $\begin{array}{l}\text { Índice agregado sobre os direitos dos acionistas, com base no } \\
\text { índice original de anti-directors rights construído por La } \\
\text { Porta et al. (1998). O índice original varia entre } 0 \text { e } 5 \text {, porém } \\
\text { alterou-se de forma que varie entre } 0 \text { e } 1 \text {. }\end{array}$ & $\begin{array}{l}\text { Djankov, La Porta et al. } \\
(2008)\end{array}$ \\
\hline
\end{tabular}

Nota. Lista, descrição e fontes dos indicadores utilizados para compor os indicadores de proteção dos acionistas e credores.

A Figura 1 apresenta a distribuição dos países de acordo com o grau de proteção a acionistas e credores. No eixo das abcissas plota-se o indicador de proteção ao acionista minoritário e no eixo das ordenadas o indicador de proteção aos direitos dos credores. A fim de classificar os países de acordo com o nível de proteção dado a cada grupo de investidores, utiliza-se a mediana de cada indicador, designando-se então dummies para cada quadrante respectivamente. O quadrante denotado por $\mathrm{HH}$ (em conotação a High-High) comporta os países que possuem alta proteção para os dois grupos de investidores (dummy $\mathrm{D}_{\mathrm{HH}}$ ); o quadrante LL (em conotação a Low-Low), agrega os países que possuem baixa proteção aos dois grupos de investidores (dummy $\left.\mathrm{D}_{\mathrm{LL}}\right)$; LH reúne os países que possuem, 
simultaneamente, baixa proteção aos acionistas e alta proteção aos credores (dummy $\mathrm{D}_{\mathrm{LH}}$ ); finalmente, o quadrante HL abriga países que possuem, simultaneamente, alta proteção aos acionistas e baixa proteção aos credores (dummy $\mathrm{D}_{\mathrm{HL}}$ ).

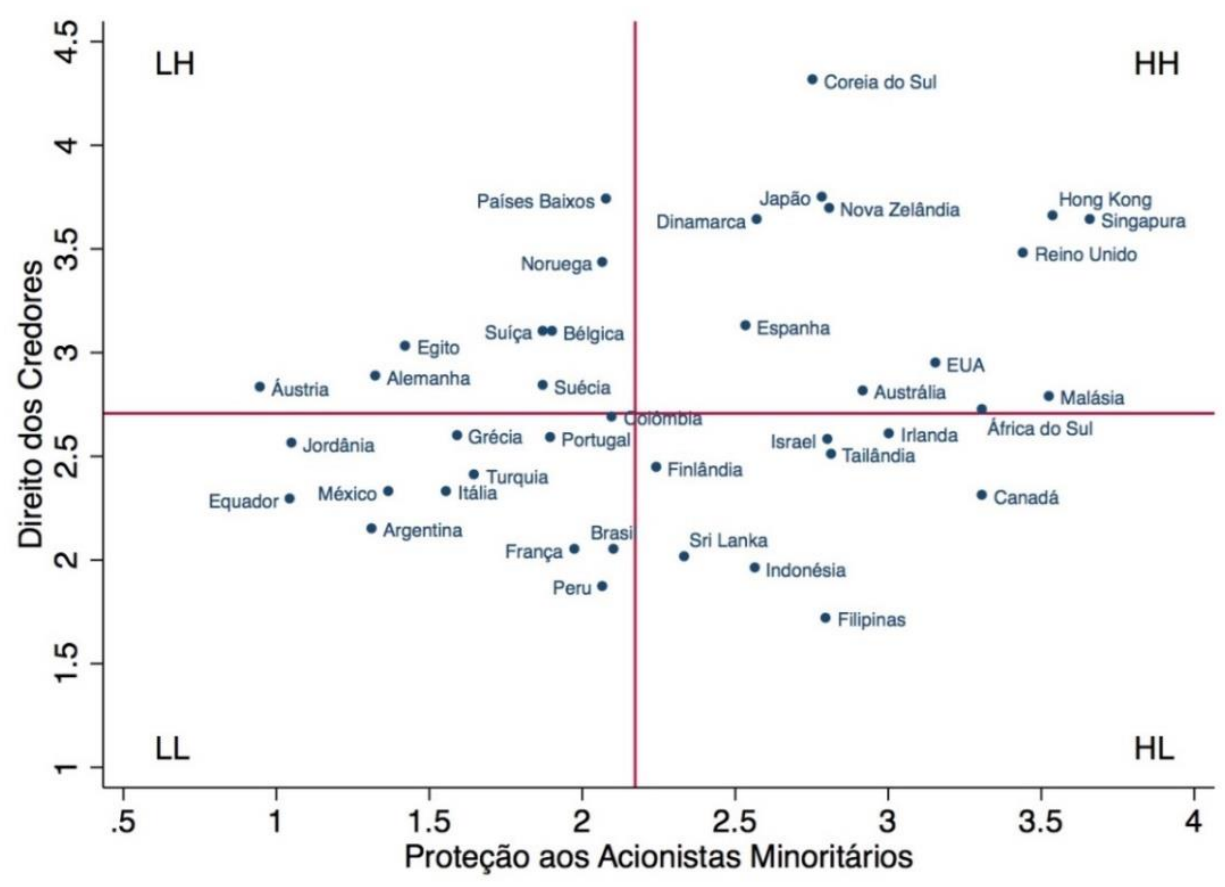

Figura 1. Dispersão dos Países em Relação à Proteção dos Investidores

\section{Modelo}

Na literatura não existe um modelo que seja unânime para analisar a estrutura de capital e os seus determinantes. Este trabalho opta pela metodologia de dados em painel. O modelo é baseado em Cheng e Shiu (2007), porém com adaptações relacionadas à proteção do investidor, além de variáveis macroeconômicas e características da firma. O modelo estimado é representado pela equação abaixo:

$$
\begin{aligned}
& \text { Alavancagem }_{i t}= \\
& \begin{aligned}
\beta_{0}+\boldsymbol{\alpha} \boldsymbol{X}+\boldsymbol{\gamma} \boldsymbol{W} & +\beta_{1} D_{H H}+\beta_{2} D_{H L}+\beta_{3} D_{L H}+\beta_{4} \text { Tangibilidade }_{i t} \times D_{H H} \\
& +\beta_{5} \text { Tangibilidade }_{i t} \times D_{H L}+\beta_{6} \text { Tangibilidade }_{i t} \times D_{L H}+\varepsilon_{i t}
\end{aligned}
\end{aligned}
$$

Onde:

$$
\begin{gathered}
\begin{array}{r}
\boldsymbol{X} \boldsymbol{X}=\alpha_{1} \text { Oportunidade de Crescimento }_{i t}+\alpha_{2} \text { Tamanho }_{i t}+\alpha_{3} \text { Lucratividade }_{i t} \\
+\alpha_{4} \text { Incerteza do Negócio }_{i t}+\alpha_{5} \text { Tangibilidade }_{i t}
\end{array} \\
\begin{array}{c}
\mathrm{e}: \\
\boldsymbol{\gamma} \boldsymbol{W}=\gamma_{1} \text { Desenvolvimento Econômico }_{c t}+\gamma_{2} \text { Inflação }_{c t}+\gamma_{3} \text { Alíquota de IR Jurídico }_{c t} \\
+\gamma_{4} \text { Dummy Loss Carryback }_{c}
\end{array}
\end{gathered}
$$

Subscritos $i, c$ e $t$ representam a empresa $i$ do país $c$ no período $t$. As interações da variável de tangibilidade com as dummies dos quadrantes segundo o nível de proteção dos investidores fizeram-se necessárias, pois, em países com alta proteção aos direitos dos credores, como o enforcement das leis é maior (Djankov, La Porta, Lopezde-Silanes, \& Shleifer, 2003; Djankov, Hart et al., 2008), é possível que o nível de endividamento dependa mais dos ativos tangíveis. De maneira similar, em países com baixa proteção aos credores, um alto valor de ativos 
tangíveis pode não ter muita influência com o nível de alavancagem. O modelo de regressão foi estimado com dados em painel desbalanceado, com efeitos fixos (FE) de ano e indústria, e com erros clusterizados ao nível de país.

Endogenia costuma ser um problema central em qualquer investigação empírica em finanças corporativas. Entende-se que possa haver endogenia entre as variáveis a nível de empresa apesar da mitigação usualmente oferecida pela estrutura de dados em painel. Por isso, considera-se tais variáveis apenas como moderadoras ou controles para o modelo proposto. Não é pretensão desse trabalho afirmar relação de causalidade entre tais variáveis. Contudo, a relação de principal interesse nesta pesquisa é entre os indicadores de proteção aos investidores a nível de país e a alavancagem a nível de empresa. Evidentemente, essa relação não está sujeita à endogenia, posto que a alavancagem de uma empresa não afetaria o grau de proteção dos investidores do seu país. Os resultados serão discutidos dentro dessa perspectiva.

\section{Resultados}

A Tabela 4 apresenta os resultados da estimação da equação 2. A primeira coluna dessa tabela corresponde a um modelo estimado por Mínimos Quadrados Ordinários (MQO) com erros clusterizados por país, incluindo a interação entre Tangibilidade e as dummies dos quadrantes e, nas três colunas seguintes, adicionando-se efeitos fixos de ano, indústria e ambos (omitidos em benefício da concisão, mas presentes na estimação onde indicado).

Os resultados apresentam uma relação negativa entre alavancagem e lucratividade, o que sugere que o endividamento ocorre após o esgotamento dos recursos próprios, e uma relação positiva entre endividamento e oportunidades de investimentos, que indica que as empresas que investem mais apresentam um maior endividamento. Tais resultados favorecem as previsões da Teoria da Pecking Order (Myers \& Majluf, 1984).

Tabela 4

\section{Determinantes da Alavancagem Corporativa}

\begin{tabular}{lccccc}
\hline Variáveis & $(1)$ & $(2)$ & $(3)$ & $(4)$ & $(5)$ \\
& & MQO & FE Ano & FE Ind. & FE Ano \& Ind. \\
\hline Op. de Crescimento & + & $0,02^{* * *}$ & $0,02^{* * *}$ & $0,02^{* * *}$ & $0,02^{* * *}$ \\
Tamanho & & {$[8,12]$} & {$[8,36]$} & {$[8,17]$} & {$[8,37]$} \\
& + & $0,03^{* * *}$ & $0,03^{* * *}$ & $0,03^{* * *}$ & $0,03^{* * *}$ \\
Lucratividade & - & {$[12,68]$} & {$[12,69]$} & {$[14,62]$} & {$[14,58]$} \\
& & $-0,72^{* * *}$ & $-0,72^{* * *}$ & $-0,71^{* * *}$ & $-0,71^{* * *}$ \\
Incerteza do Negócio & - & $-0,55^{* * *}$ & $-0,55^{* * *}$ & $-0,36^{* * *}$ & $-0,36^{* * *}$ \\
& & {$[-4,81]$} & {$[-4,87]$} & {$[-4,51]$} & {$[-4,56]$} \\
Tangibilidade & + & $-0,18^{* * *}$ & $-0,18^{* * *}$ & $-0,16^{* * *}$ & $-0,16^{* * *}$ \\
& & {$[-9,24]$} & {$[-9,49]$} & {$[-7,81]$} & {$[-7,88]$} \\
Loss Carryback & - & $-0,04^{* *}$ & $-0,04^{* *}$ & $-0,04^{*}$ & $-0,04^{* * *}$ \\
IR Empresarial & & {$[-2,81]$} & {$[-2,97]$} & {$[-2,70]$} & {$[-2,89]$} \\
& - & $-0,09$ & $-0,15^{*}$ & $-0,10$ & $-0,16^{*}$ \\
& & {$[-1,41]$} & {$[-2,03]$} & {$[-1,71]$} & {$[-2,30]$} \\
\hline
\end{tabular}

Continua 


\section{Tabela 4 (continuação)}

\begin{tabular}{|c|c|c|c|c|c|}
\hline Variáveis & (1) & $\begin{array}{c}(2) \\
\text { MQO }\end{array}$ & $\begin{array}{c}(3) \\
\text { FE Ano }\end{array}$ & $\begin{array}{c}(4) \\
\text { FE Ind. }\end{array}$ & FE Ano \& Ind. \\
\hline \multirow[t]{2}{*}{ Crescimento PIB } & + & $-0,00$ & $-0,00$ & $-0,00$ & $-0,00$ \\
\hline & & {$[-0,66]$} & {$[-1,09]$} & {$[-0,68]$} & {$[-1,13]$} \\
\hline \multirow[t]{2}{*}{ Inflação } & + & $0,23^{*}$ & 0,17 & $0,24^{*}$ & 0,19 \\
\hline & & {$[2,08]$} & {$[1,59]$} & {$[2,46]$} & {$[1,94]$} \\
\hline \multirow[t]{2}{*}{$\mathrm{D}_{\mathrm{LH}}$} & & $-0,06^{* *}$ & $-0,06^{* *}$ & $-0,07^{* * *}$ & $-0,07^{* * * *}$ \\
\hline & & {$[-3,04]$} & {$[-3,18]$} & {$[-3,79]$} & {$[-3,96]$} \\
\hline \multirow[t]{2}{*}{$\mathrm{D}_{\mathrm{HL}}$} & & $-0,04^{*}$ & $-0,04^{*}$ & $-0,05^{*}$ & $-0,05^{*}$ \\
\hline & & {$[-2,30]$} & {$[-2,31]$} & {$[-2,61]$} & {$[-2,61]$} \\
\hline \multirow[t]{2}{*}{$\mathrm{D}_{\mathrm{HH}}$} & & $-0,10^{* * * *}$ & $-0,10^{* * *}$ & $-0,11^{\text {**** }}$ & $-0,11^{* * *}$ \\
\hline & & {$[-5,36]$} & {$[-5,48]$} & {$[-5,98]$} & {$[-6,12]$} \\
\hline \multirow[t]{2}{*}{ Tangibilidade $x D_{L H}$} & & $0,18^{* * *}$ & $0,18^{* * *}$ & $0,18^{* * *}$ & $0,18^{* * *}$ \\
\hline & & {$[3,78]$} & {$[3,76]$} & {$[4,01]$} & {$[3,98]$} \\
\hline \multirow[t]{2}{*}{ Tangibilidade $x D_{H L}$} & & $0,08^{* *}$ & $0,09^{* *}$ & $0,12^{* * *}$ & $0,12^{* * * *}$ \\
\hline & & {$[2,99]$} & {$[3,06]$} & {$[5,01]$} & {$[5,22]$} \\
\hline \multirow[t]{2}{*}{ Tangibilidade x $\mathrm{D}_{\mathrm{HH}}$} & & $0,21^{* * *}$ & $0,21^{* * *}$ & $0,22^{* * *}$ & $0,22^{* * *}$ \\
\hline & & {$[5,29]$} & {$[5,28]$} & {$[5,70]$} & {$[5,66]$} \\
\hline \multirow[t]{2}{*}{ Constante } & & $-0,05$ & $-0,02$ & $-0,10^{*}$ & $-0,07$ \\
\hline & & {$[-0,93]$} & {$[-0,35]$} & {$[-2,09]$} & {$[-1,46]$} \\
\hline Observações & & 59.588 & 59.588 & 59.588 & 59.588 \\
\hline R-Quadrado & & 0,23 & 0,24 & 0,28 & 0,28 \\
\hline FE Ano & & Não & Sim & Não & Sim \\
\hline FE Indústria & & Não & Não & Sim & Sim \\
\hline
\end{tabular}

Nota. Regressão com dados em painel. A variável explicada é a alavancagem financeira. As proxies utilizadas para as variáveis explicativas foram descritas na Tabela 2. Valores entre colchetes são estatísticas t calculadas com erros-padrão clusterizados por país. *, ** e *** denotam significância aos níveis de $5 \%, 1 \%$ e $0,1 \%$ respectivamente.

Os coeficientes negativos das dummies de quadrante indicam que, na média, empresas em países dos quadrantes HH, HL e LH endividam-se menos do que as empresas em países no quadrante LL. O fator disciplinador da dívida introduzido por Jensen (1986), é uma possível explicação para esse resultado. Nesse quadrante, com baixa proteção aos investidores, o acionista minoritário acaba por se beneficiar pela alavancagem da empresa, uma vez que a dívida possui efeito disciplinador sobre a discricionariedade dos executivos. Nesse quadrante, pode-se inferir que a tolerância ao risco por parte dos investidores é maior, justamente pelos maiores obstáculos da empresa em adquirir financiamento externo. Outra possível explicação, ainda, seria a transferência de risco para o credor. Se a empresa esgotou todos os seus recursos internos e ainda necessita de capital, pela POT ela deveria recorrer aos credores, o que levaria a um maior nível de alavancagem. Portanto, esse resultado sugere que as empresas desse quadrante tomam decisões de estrutura de capital que seguem a POT.

De acordo com os resultados da Tabela 4, é possível estabelecer a seguinte ordem em termos de grau de alavancagem entre os quadrantes: $D_{L L}>D_{H L}>D_{L H}>D_{H H}$. Empresas nos quadrantes com alta proteção aos direitos dos acionistas são, em média, menos alavancadas do que empresas em países com baixa proteção aos 
acionistas. Isso indica que os MEG associados à proteção do acionista de fato influenciam na escolha pela estrutura de capital da empresa.

Todas as relações encontradas indicam que o aumento na proteção de qualquer dos investidores está associado à diminuição da alavancagem. Isto é, tanto a relação $D_{L L}>D_{H L}$ quanto a relação $D_{L L}>D_{L H}$ indicam que o aumento tanto de proteção ao acionista quanto de proteção aos credores está associado a menos alavancagem. Além disso, as relações $D_{H L}>D_{H H}$ e $D_{L H}>D_{H H}$ indicam o mesmo efeito: o aumento de proteção diminui a alavancagem.

Empresas em países nos quadrantes HH e HL são menos alavancadas, na média, do que empresas em países nos quadrantes LH e LL, respectivamente. Isso está em linha com a hipótese de que a proteção ao acionista diminui a propensão da empresa tomar dívida, o que está de acordo com a hipótese $\mathrm{H}_{1 \mathrm{~b}}$. Analogamente, o aumento da proteção aos credores tem o mesmo efeito no nível de dívida, de onde se pode inferir, portanto, que quando credores têm acesso à informação e maior poder de enforcement, a alavancagem é menor. Esse resultado corrobora Acharya et al. (2011) e está de acordo com a hipótese $\mathrm{H}_{2 \mathrm{a}}$.

Além do fator disciplinador da dívida introduzido por Jensen (1986) e da possível transferência de risco entre os investidores, com o objetivo de analisar se existe algum outro fator que pode ter levado ao resultado das empresas no quadrante LL serem mais endividadas, procedeu-se com a verificação entre a média de alavancagem nos países em relação a todos os países a amostra. A Figura 2 revela que em todos os quadrantes há uma distribuição quase homogênea entre os países com alavancagem acima ou abaixo da média global. Isso indica que, além dos MEG, os fatores no nível da firma são decisivos para a escolha do endividamento e, ainda, que podem existir fatores relacionados aos mecanismos internos de governança que potencialmente ainda não foram incorporados ao modelo e que podem afetar a decisão da empresa na escolha da sua estrutura de capital.

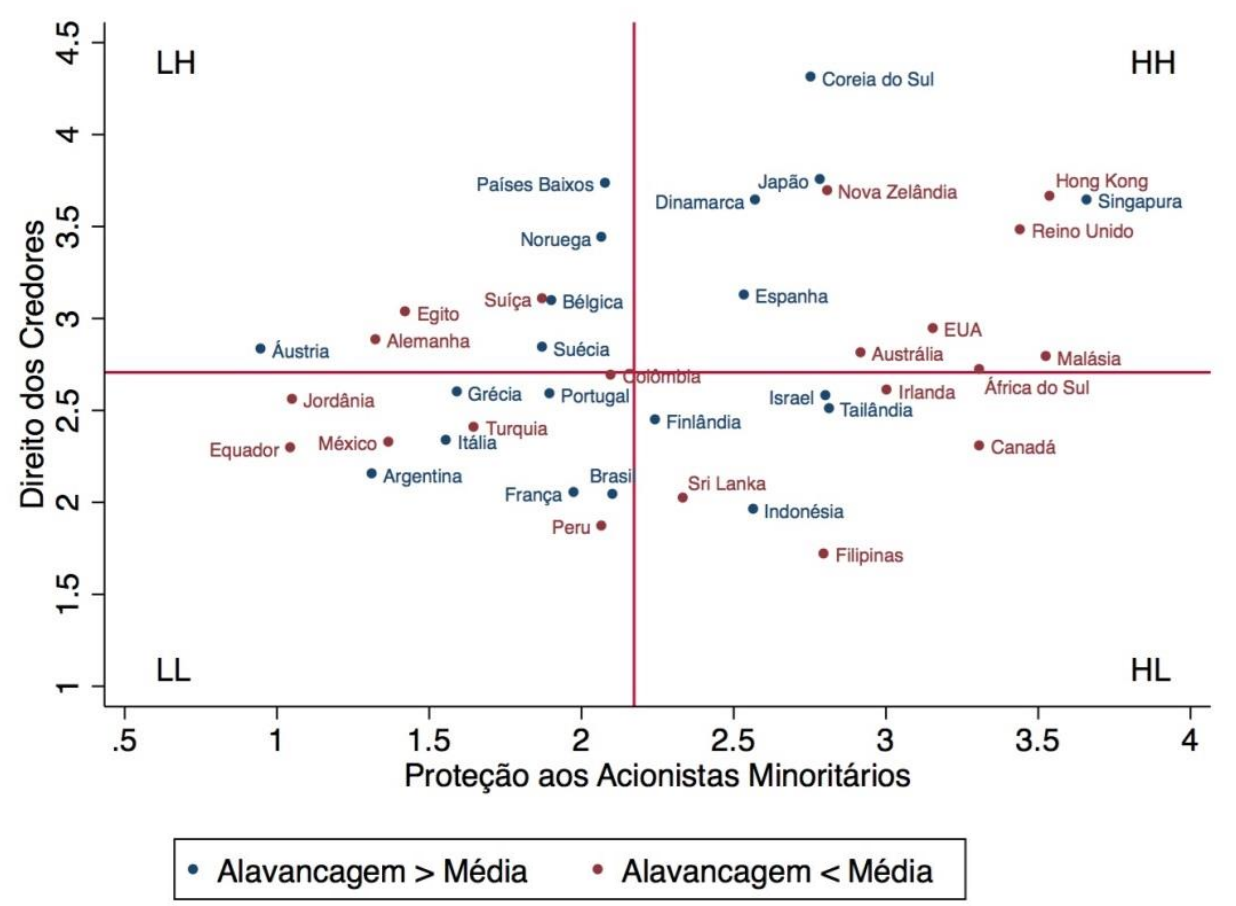

Figura 2. Dispersão dos Países em Relação à Proteção dos Investidores com Separação pelo Nível de Alavancagem

O coeficiente negativo da tangibilidade está de acordo com o que foi encontrado em Cheng e Shiu (2007). As interações de tangibilidade com as dummies de proteção aos investidores apresentaram sinal positivo e significativos. Isso indica que os ativos tangíveis são importantes para servir de colateral da dívida, principalmente em países com maior proteção aos investidores. Almeida e Campello (2007) encontraram resultados na mesma 
linha e concluíram que os ativos que são mais tangíveis sustentam mais financiamento externo porque esses ativos atenuam os problemas de contratação: a tangibilidade aumenta o valor que pode ser capturado pelos credores em estados de inadimplência. Em países com baixa proteção ao credor, o poder de enforcement é baixo. Nesse cenário, o fato de a empresa ter ativos tangíveis em caixa para usar como colateral não tem um peso alto, uma vez que o credor tampouco tem poder de enforcement em uma situação de default. Observa-se que os coeficientes das interações são maiores justamente nos quadrantes HH e LH, que representam países com forte proteção aos direitos dos credores, o que corrobora essa interpretação. Nota-se também que o efeito positivo da tangibilidade é maior para avanços na proteção aos direitos dos credores do que para melhorias na proteção aos acionistas minoritários. Isso é coerente com a proposição de que os colaterais são mais valiosos para os credores do que para os acionistas.

Por fim, o coeficiente da variável Loss Carryback apresenta sinal negativo, conforme o esperado. Isso sugere que as empresas em países em que é permitido o uso de loss carryback como substituto ao benefício fiscal utilizam menos dívida. Por outro lado, o coeficiente da variável da alíquota do IR empresarial só é significativo em uma das regressões e, ainda assim, com baixa significância. Graham (2003) destaca que, do ponto de vista empírico, a magnitude do efeito dos impostos na estrutura de capita nem sempre é grande. Ainda, o coeficiente da alíquota do IR empresarial apresenta sinal negativo, o que é diferente do esperado. Isso pode indicar, entre outras coisas, que o IR empresarial não é a melhor opção de proxy para o benefício fiscal da dívida, mas sim a proxy proposta por Miller (1977), que inclui os impostos de pessoa física e, por isso, considera o efeito marginal do benefício fiscal da dívida. Nessa linha, Faccio e Xu (2015) encontram resultados que indicam que tanto os impostos corporativos quanto os pessoais são determinantes na escolha da estrutura de capital das empresas. Finalmente, o coeficiente positivo e significante da inflação em dois modelos sugere que as empresas aproveitam o momento da economia aquecida para emitir dívidas e aumentar o investimento da empresa. Isso sugere que empresas em países com maior inflação estão mais dispostas a utilizar dívidas do que empresas em países com menor taxa de inflação.

\section{Testes de robustez}

Para checar a robustez do modelo, alterna-se diferentes especificações para o modelo baseline. Esses resultados são apresentados na Tabela 5. Pelo fato das variáveis de proteção aos credores e aos acionistas minoritários serem compostas por índices de proteção dos investidores que agregam informações macroeconômicas, surge a dúvida se as variáveis macroeconômicas utilizadas no modelo não estariam absorvendo fatores explicativos das dummies dos quadrantes. Estima-se, então, um modelo sem as variáveis macroeconômicas (coluna 2 da Tabela 5) e os resultados não sofrem alterações substanciais.

Tabela 5

\section{Testes de Robustez}

\begin{tabular}{lccccc}
\hline Variáveis & $(1)$ & $(2)$ & $(3)$ & $(4)$ & $(5)$ \\
\hline Op. de Crescimento & + & $0,02^{* * *}$ & $0,03^{* * *}$ & $0,02^{* * * *}$ & $0,02^{* * *}$ \\
\multirow{2}{*}{ Tamanho } & & {$[6,72]$} & {$[8,35]$} & {$[7,89]$} & {$[12,65]$} \\
& + & $0,03^{* * *}$ & $0,03^{* * *}$ & $0,03^{* * *}$ & $0,03^{* * *}$ \\
Lucratividade & - & {$[14,39]$} & {$[14,79]$} & {$[14,45]$} & {$[14,28]$} \\
& $-0,70^{* * *}$ & $-0,71^{* * *}$ & $-0,72^{* * *}$ & $-0,65^{* * *}$ \\
Incerteza do Negócio & - & {$[-10,16]$} & {$[-10,82]$} & {$[-10,89]$} & {$[-10,84]$} \\
& $-0,38^{* * *}$ & $-0,36^{* * *}$ & $-0,36^{* * *}$ & $-0,47^{* * *}$ \\
& & {$[-4,07]$} & {$[-4,59]$} & {$[-4,49]$} & {$[-6,33]$} \\
\hline
\end{tabular}

Continua 
Tabela 5 (continuação)

\begin{tabular}{|c|c|c|c|c|c|}
\hline Variáveis & (1) & (2) & (3) & (4) & (5) \\
\hline \multirow[t]{2}{*}{ Tangibilidade } & + & $-0,15^{* * *}$ & $-0,14^{* * *}$ & $-0,15^{* * *}$ & $-0,15^{* * *}$ \\
\hline & & {$[-8,31]$} & {$[-6,77]$} & {$[-8,01]$} & {$[-7,64]$} \\
\hline \multirow[t]{2}{*}{ Loss Carryback } & - & & $-0,04^{* * *}$ & $-0,03^{*}$ & $-0,05^{* *}$ \\
\hline & & & {$[-3,07]$} & {$[-2,14]$} & {$[-3,14]$} \\
\hline \multirow[t]{2}{*}{ IR Empresarial } & - & & $-0,14^{*}$ & $-0,15^{*}$ & $-0,05$ \\
\hline & & & {$[-2,08]$} & {$[-2,19]$} & {$[-0,41]$} \\
\hline \multirow[t]{2}{*}{ Crescimento PIB } & + & & $-0,00$ & $-0,00$ & $-0,00$ \\
\hline & & & {$[-0,70]$} & {$[-0,74]$} & {$[-1,58]$} \\
\hline \multirow[t]{2}{*}{ Inflação } & + & & $0,31^{* * *}$ & 0,08 & 0,09 \\
\hline & & & {$[3,73]$} & {$[0,82]$} & {$[0,77]$} \\
\hline \multirow[t]{2}{*}{$\mathrm{D}_{\mathrm{LH}}$} & & $-0,08^{* * * *}$ & $-0,07^{* * *}$ & $-0,05^{*}$ & $-0,06^{* *}$ \\
\hline & & {$[-4,51]$} & {$[-4,36]$} & {$[-2,54]$} & {$[-3,28]$} \\
\hline \multirow[t]{2}{*}{$\mathrm{D}_{\mathrm{HL}}$} & & $-0,05^{*}$ & $-0,05^{*}$ & $-0,03$ & $-0,04$ \\
\hline & & {$[-2,16]$} & {$[-2,49]$} & {$[-1,36]$} & {$[-1,89]$} \\
\hline \multirow[t]{2}{*}{$\mathrm{D}_{\mathrm{HH}}$} & & $-0,12^{* * * *}$ & $-0,11^{* * *}$ & $-0,07^{* *}$ & $-0,07^{* * *}$ \\
\hline & & {$[-6,67]$} & {$[-6,81]$} & {$[-3,28]$} & {$[-3,87]$} \\
\hline \multirow[t]{2}{*}{ Tangibilidade $x D_{L H}$} & & $0,18^{* * *}$ & $0,17^{* * * *}$ & $0,18^{* * *}$ & $0,17^{* * * *}$ \\
\hline & & {$[3,68]$} & {$[3,72]$} & {$[4,13]$} & {$[3,65]$} \\
\hline \multirow[t]{2}{*}{ Tangibilidade $\mathrm{x} \mathrm{D}_{\mathrm{HL}}$} & & $0,09^{* * * *}$ & $0,10^{* * *}$ & $0,12^{* * * *}$ & $0,11^{* * * *}$ \\
\hline & & {$[4,44]$} & {$[4,75]$} & {$[5,27]$} & {$[5,25]$} \\
\hline \multirow[t]{2}{*}{ Tangibilidade $x D_{H H}$} & & $0,21^{* * * *}$ & $0,20^{* * *}$ & $0,21^{* * * *}$ & $0,14^{* * * *}$ \\
\hline & & {$[5,86]$} & {$[5,21]$} & {$[5,58]$} & {$[4,07]$} \\
\hline \multirow[t]{2}{*}{ Emergentes } & & & $-0,02$ & & \\
\hline & & & {$[-1,87]$} & & \\
\hline \multirow[t]{2}{*}{ Origem Francesa } & & & & $0,04^{*}$ & \\
\hline & & & & {$[2,27]$} & \\
\hline \multirow[t]{2}{*}{ Origem Alemã } & & & & $-0,01$ & \\
\hline & & & & {$[-0,43]$} & \\
\hline \multirow[t]{2}{*}{ Origem Escandinava } & & & & 0,04 & \\
\hline & & & & {$[1,80]$} & \\
\hline \multirow[t]{2}{*}{ Constante } & & $-0,08$ & $-0,07$ & $-0,11^{*}$ & $-0,08$ \\
\hline & & {$[-1,78]$} & {$[-1,50]$} & {$[-2,15]$} & {$[-1,37]$} \\
\hline Observações & & 59.588 & 59.588 & 59.588 & 40.959 \\
\hline R-Quadrado & & 0,27 & 0,28 & 0,28 & 0,31 \\
\hline
\end{tabular}

Nota. Regressão com dados em painel. A variável explicada é a alavancagem financeira. As proxies utilizadas para as variáveis explicativas foram descritas na Tabela 2. Todas as regressões incluem efeitos fixos de ano e indústria. Valores entre colchetes são estatísticas t calculadas com erros-padrão clusterizados por país. *, ** e *** denotam significância aos níveis de 5\%,1\% e $0,1 \%$ respectivamente. 
De acordo com a Figura 3, é possível observar que os países emergentes se encontram majoritariamente nos quadrantes com baixa proteção ao credor. Com o argumento de que os indicadores de proteção dos investidores potencialmente não controlam para esse fato, inclui-se uma dummy para os mercados emergentes na equação 1 como teste de robustez. Os resultados (coluna 3 da Tabela 5) não apresentam alterações significativas, o que indica que o modelo é robusto para essa variável de controle.

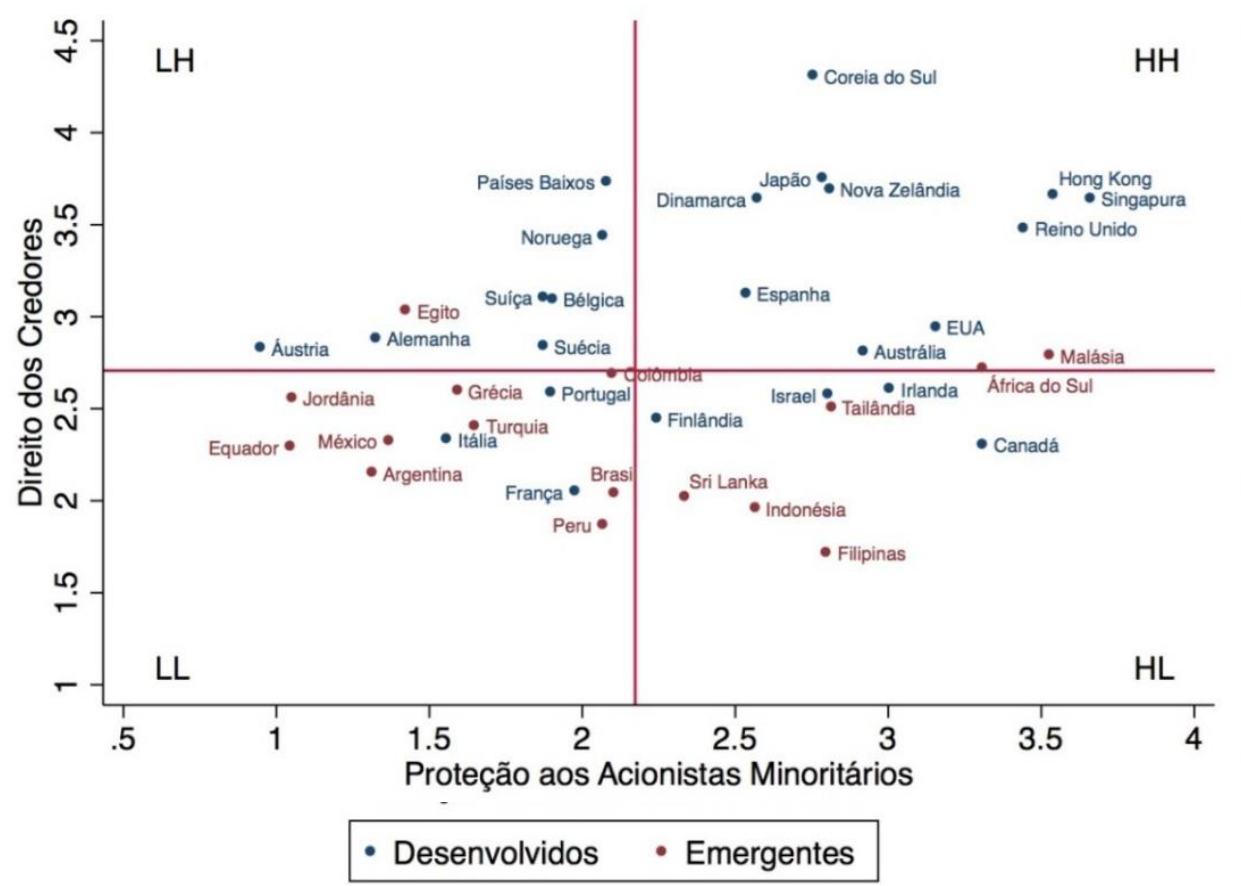

Figura 3. Dispersão dos Países em Relação à Proteção dos Investidores com Separação pelo Nível de Desenvolvimento da Economia

A argumentação central de La Porta et al. $(1998,2000)$ é que a proteção aos investidores decorre da origem do sistema legal dos países. Nesse sentido, os indicadores de proteção para credores e acionistas utilizados nesta pesquisa seriam apenas proxies para aqueles determinantes. Para investigar tal possibilidade, emprega-se dummies de origem legal dos países no modelo. A inclusão dessas dummies de controle também não altera os resultados principais de maneira substancial (vide coluna 4 da Tabela 5). Isso sugere que os indicadores de proteção dos investidores incorporam nova informação ao modelo. Finalmente, testa-se a possibilidade de que os resultados sejam provocados pelos países com alta representatividade na amostra (Coreia do Sul e Japão). A coluna 5 da Tabela 5 apresenta os resultados da estimação com a exclusão desses dois países. Conforme pode ser contatado, os resultados principais não se modificam. Portanto, conclui-se que o modelo utilizado para analisar o grau de alavancagem entre as empresas em relação ao nível de proteção dos investidores é robusto a esses questionamentos. Adicionalmente, como teste de robustez final, estimou-se os modelos da Tabela 4 através do Mínimos Quadrados Ordinários Ponderados, ponderando-se as observações pelo inverso de sua probabilidade de inclusão na amostra. Observou-se que os resultados se mantiveram semelhantes aos originais (resultados omitidos para fins de concisão, mas disponíveis mediante solicitação aos autores).

\section{Conclusão}

Este trabalho tem o objetivo de investigar de que forma os Mecanismos de Governança externos à firma impactam a alavancagem corporativa em uma amostra de 7.490 empresas de 40 países. Os estudos de estrutura de capital entre países possuem a desvantagem de que peculiaridades de certos países são eventualmente ignoradas. Apesar disso, com este tipo de pesquisa, é possível investigar questões que não poderiam ser respondidas com a 
análise de um único país. Particularmente, esta pesquisa diferencia-se das anteriores ao fazer distinção entre os MEG que afetam a proteção dos acionistas minoritários daqueles que afetam os direitos dos credores.

De maneira consistente com estudos prévios sobre alavancagem financeira (Booth et al., 2001; Cheng \& Shiu, 2007; Jong et al., 2008; Fan et al., 2012; Rajan \& Zingales, 1995), esta pesquisa empírica analisa o efeito conjunto entre características no nível da firma e atributos de governança no nível país na decisão de estrutura de capital da firma e, ainda, utiliza a distinção entre os níveis de proteção dos investidores entre países para averiguar se a escolha pelo grau de alavancagem da empresa é coerente com o previsto pela Teoria da Pecking Order (POT).

Os resultados encontrados foram em linha com o previsto pelas hipóteses. Os coeficientes das variáveis de controle no nível da firma são coerentes com o previsto pela POT. É possível estabelecer a seguinte ordem em termos de grau de alavancagem entre os quadrantes: $D_{L L}>D_{L H}>D_{H H}>D_{H L}$. Empresas nos quadrantes com alta proteção aos direitos dos acionistas são, em média, menos alavancadas do que empresas em países com baixa proteção aos acionistas. Isso indica que os MEG associados à proteção do acionista de fato influenciam na escolha pela estrutura de capital da empresa. O mesmo acontece quando se analisa a melhora na proteção dos direitos dos credores: observa-se diminuição no uso de endividamento. Os resultados mostram-se robustos frente a diferentes especificações no modelo. Esta pesquisa sugere que maior proteção aos investidores torna as firmas menos propensas à utilização de capital de terceiros. Isso pode ser motivado pela aversão dos insiders (executivos e acionistas majoritários) ao papel moderador da dívida sobre sua discricionariedade gerencial. Dessa forma, uma contribuição gerencial que emana dessa pesquisa é o papel moderador do endividamento na mitigação dos conflitos de agência inerentes às sociedades por ações. Da mesma forma, os resultados discutidos aqui sugerem às autoridades reguladoras a importância de desenvolver mecanismos institucionais adequados de proteção aos interesses de ambas classes de investidores: acionistas e credores.

Uma limitação deste trabalho é que os MEG utilizados para construir os indicadores são estáticos no tempo. Apesar de que, por definição, instituições são estáveis no curto prazo e mudanças institucionais são raras, esta limitação é legítima. Como pesquisa futura pretende-se utilizar indicadores dinâmicos de proteção dos investidores. $\mathrm{O}$ efeito de mudanças institucionais sobre a alavancagem corporativa é um aspecto que pode revelar novos insights sobre esse problema. Outra limitação é a ausência de controles para os mecanismos internos de governança. O efeito dessas variáveis e sua interação com os MEG sobre a alavancagem da empresa certamente é um aspecto ainda desconhecido. Entretanto, a sua implementação empírica ainda representa um desafio em termos de relações endógenas.

\section{Nota}

\footnotetext{
${ }^{1}$ Os indicadores propostos por La Porta et al. (1998) são objeto de críticas na literatura em função da metodologia empregada em sua construção (e.g., Armour, J., Deakin, S., Sarkar, P., Siems, M., \& Singh, A. (2009). Shareholder protection and stock market development: An empirical test of the legal origins hypothesis. Journal of Empirical Legal Studies, 6(2), 343-380. https://doi.org/10.1111/j.17401461.2009.01146.x; Siems, M. (2005). What does not work in comparing securities laws: A critique on La Porta et al. 's methodology [CPCRPS No. 0009]. Recuperado de https://ssrn.com/abstract=608644; Spamann, H. (2010). The "antidirector rights index" revisited. Review of Financial Studies, 23(2), 467-486. https://doi.org/10.1093/rfs/hhp067). Contudo, em benefício da comparabilidade dos resultados dessa pesquisa com a literatura internacional contemporânea, opta-se por utilizar os indicadores originais ao invés de outros alternativos pois ainda hoje em dia eles são os mais amplamente utilizados na literatura empírica, apesar dos questionamentos. Agradecemos a um avaliador anônimo por esse comentário.
} 


\section{Referências}

Acharya, V. V., Amihud, Y., \& Litov, L. (2011). Creditor rights and corporate risk-taking. Journal of Financial Economics, 102(1), 150-166. https://doi.org/10.1016/j.jfineco.2011.04.001

Almeida, H., \& Campello, M. (2007). Financial constraints, asset tangibility, and corporate investment. Review of Financial Studies, 20(5), 1429-1460. https://doi.org/10.1093/rfs/hhm019

Bancel, F., \& Mittoo, U. R. (2004). Cross-country determinants of capital structure choice: a survey of European firms. Financial Management, 33(4),103-132. Retrieved from https://www.jstor.org/stable/3666330

Booth, L., Aivazian, V., Demirgüç-Kunt, A., \& Maksimovic, V. (2001). Capital structures in developing countries. The Journal of Finance, 56(1), 87-130. https://doi.org/10.1111/0022-1082.00320

Cheng, S.-R., \& Shiu, C.-Y. (2007). Investor protection and capital structure: International evidence. Journal of Multinational Financial Management, 17(1), 30-44. https://doi.org/10.1016/j.mulfin.2006.03.002

Demirgüç-Kunt, A., \& Maksimovic, V. (1999). Institutions, financial markets, and firm debt maturity. Journal of Financial Economics, 54(3), 295-336. https://doi.org/10.1016/s0304-405x(99)00039-2

Denis, D. K., \& McConnell, J. J. (2003). International corporate governance. Journal of Financial and Quantitative Analysis, 38(1), 1-36. https://doi.org/10.2307/4126762

Djankov, S., Hart, O., McLiesh, C., \& Shleifer, A. (2008). Debt enforcement around the world. Journal of Political Economy, 116(6), 1105-1149. https://doi.org/10.1086/595015

Djankov, S., La Porta, R., Lopez-de-Silanes, F., \& Shleifer, A. (2003). Courts. The Quarterly Journal of Economics, 118(2), 453-517. https://doi.org/10.1162/003355303321675437

Djankov, S., La Porta, R., Lopez-de-Silanes, F., \& Shleifer, A. (2008). The law and economics of self-dealing. Journal of Financial Economics, 88(3), 430-465. https://doi.org/10.1016/j.jfineco.2007.02.007

Djankov, S., McLiesh, C., \& Shleifer, A. (2007). Private credit in 129 countries. Journal of Financial Economics, 84(2), 299-329. https://doi.org/10.1016/j.jfineco.2006.03.004

Faccio, M., \& Xu, J. (2015). Taxes and capital structure. Journal of Financial and Quantitative Analysis, 50(3), 277-300. https://doi.org/10.1017/S0022109015000174

Fama, E. F., \& French, K. R. (1997). Industry costs of equity. Journal of Financial Economics, 43(2), 153-193. https://doi.org/10.1016/s0304-405x(96)00896-3

Fan, J. P. H., Titman, S., \& Twite, G. (2012). An international comparison of capital structure and debt maturity choices. Journal of Financial and Quantitative Analysis, 47(1), 23-56. https://doi.org/10.1017/s0022109011000597

Frank, M. Z., \& Goyal, V. K. (2003). Testing the pecking order theory of capital structure. Journal of Financial Economics, 67(2), 217-248. https://doi.org/10.1016/S0304-405X(02)00252-0

Graham, J. R. (2003). Taxes and corporate finance: A review. Review of Financial Studies, 16(4), 1075-1129. https://doi.org/10.1093/rfs/hhg033

Jensen, M. C. (1986). Agency cost of free cash flow, corporate finance, and takeovers. Corporate Finance, and Takeovers. American Economic Review, 76(2), 323-329. Retrieved from https://www.jstor.org/stable/1818789 
Jensen, M. C., \& Meckling, W. H. (1976). Theory of the firm: Managerial behavior, agency costs and ownership structure. Journal of Financial Economics, 3(4), 305-360. https://doi.org/10.1016/0304-405x(76)90026-x

Jõeveer, K. (2013). Firm, country and macroeconomic determinants of capital structure: Evidence from transition economies. Journal of Comparative Economics, 41(1), 294-308. https://doi.org/10.1016/j.jce.2012.05.001

Jong, A. D., Kabir, R., \& Nguyen, T. T. (2008). Capital structure around the world: The roles of firm-and countryspecific determinants. Journal of Banking \& Finance, 32(9), 1954-1969. https://doi.org/10.1016/j.jbankfin.2007.12.034

La Porta, R., Lopez-de-Silanes, F., \& Shleifer, A. (2006). What works in securities laws? The Journal of Finance, 61(1), 1-32. https://doi.org/10.1111/j.1540-6261.2006.00828.x

La Porta, R., Lopez-de-Silanes, F., Shleifer, A., \& Vishny, R. (1998). Law and finance. Journal of Political Economy, 106(6), 1113-1155. https://doi.org/10.1086/250042

La Porta, R., Lopez-de-Silanes, F., Shleifer, A., \& Vishny, R. (2000). Investor protection and corporate governance. Journal of Financial Economics, 58(1), 3-27. https://doi.org/10.1016/S0304-405X(00)00065-9

Martins, H. C., Schiehll, E., \& Terra, P. R. S. (2015, August). Debt maturity and ownership: Distinctive effects of shareholder protection and creditor rights. Proceedings of Annual Meeting of the Academy of Management, Vancouver, Canada, 75. https://doi.org/10.5465/ambpp.2015.17737abstract

Miller, M. H. (1977). Debt and taxes. The Journal of Finance, 32(2), 261-275. Retrieved from http://www.jstor.org/stable/2326758?origin=JSTOR-pdf

Modigliani, F., \& Miller, M. H. (1958). The cost of capital, corporation finance and the theory of investment. American Economic Review, 48(3), 261-297. Retrieved from http://www.jstor.org/stable/1809766

Modigliani, F., \& Miller, M. H. (1963). Corporate income taxes and the cost of capital: A correction. American Economic Review, 53(3), 433-443. Retrieved from http://www.jstor.org/stable/1809167?origin=JSTOR-pdf

Myers, S. C., \& Majluf, N. S. (1984). Corporate financing and investment decisions when firms have information that investors do not have. Journal of Financial Economics, 13(2), 187-221. https://doi.org/10.1016/0304$405 \times(84) 90023-0$

Rajan, R. G., \& Zingales, L. (1995). What do we know about capital structure? Some evidence from international data. The Journal of Finance, 50(5), 1421-1460. https://doi.org/10.2307/2329322

Schiehll, E., \& Martins, H. C. (2016). Cross-national governance research: A systematic review and assessment. Corporate Governance: An International Review, 24(3), 181-199. https://doi.org/10.1111/corg.12158

Shleifer, A., \& Vishny, R. W. (1997). A survey of corporate governance. The Journal of Finance, 52(2), 737-783. https://doi.org/10.1111/j.1540-6261.1997.tb04820.x

Shyam-Sunder, L., \& Myers, S. C. (1999). Testing static tradeoff against pecking order models of capital structure. Journal of Financial Economics, 51(2), 219-244. https://doi.org/10.1016/S0304-405X(98)00051-8

Wald, J. K. (1999). How firm characteristics affect capital structure: An international comparison. Journal of Financial Research, 22(2), 161-187. https://doi.org/10.1111/j.1475-6803.1999.tb00721.x

Young, M. N., Peng, M. W., Ahlstrom, D., Bruton, G. D., \& Jiang, Y. (2008). Corporate governance in emerging economies: A review of the principal-principal perspective. Journal of Management Studies, 45(1), 196220. https://doi.org/10.1111/j.1467-6486.2007.00752.x 


\section{Autores}

Flávia F. P. Mendonça

Av. 9 de julho, 2029, Bela Vista, 01313-902, São Paulo, SP, Brasil

E-mail: flaviafurtpessoa@gmail.com

(iD) https://orcid.org/0000-0002-9225-7529

Henrique Castro Martins

Rua Marquês de São Vicente, 255, 22451-900, Rio de Janeiro, RJ, Brasil

E-mail: hcm@iag.puc-rio.br

(D) https://orcid.org/0000-0002-3186-4245

Paulo R. S. Terra

Av. 9 de julho, 2029, Bela Vista, 01313-902, São Paulo, SP, Brasil

E-mail: paulo.terra@fgv.br

(D) https://orcid.org/0000-0003-1486-120X

\section{Contribuições}

$1^{\circ}$ autor: Definição do tópico de pesquisa; redação e revisão da introdução, referencial teórico, hipóteses, método, resultados e conclusões, apresentação da pesquisa em seminários e conferências; revisão crítica geral do texto final; auxílio na manipulação dos dados.

$2^{\circ}$ autor: Revisão da introdução, referencial teórico, hipóteses, método, resultados e conclusões; manipulação e organização dos dados; estimativas empíricas e tabulação dos resultados; redação das cartas aos revisores, revisão crítica geral do texto final.

$3^{\circ}$ autor: Revisão da introdução, referencial teórico, hipóteses, método, resultados e conclusões; revisão crítica dos aspectos teóricos e definição das hipóteses de pesquisa; redação das cartas aos revisores, revisão crítica geral do texto final.

\section{Financiamento}

O presente trabalho foi realizado com os seguintes apoios: (a) Coordenação de Aperfeiçoamento de Pessoal de Nível Superior - Brasil (CAPES) - Código de Financiamento 001; (b) Conselho Nacional de Desenvolvimento Científico e Tecnológico (CNPq) processos 312347/2015-4 e 421873/2018-3; (c) bolsa de estudos provida pelo Banco ITAU; (d) 2019 AFA Doctoral Student Travel Grant.

\section{Conflito de Interesses}

Os autores informaram que não há conflito de interesses.

\section{Verificação de Plágio}

A RAC mantém a prática de submeter todos os documentos aprovados para publicação à verificação de plágio, mediante o emprego de ferramentas específicas, e.g.: iThenticate.

\section{Material Suplementar}

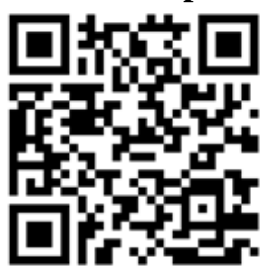

Parte dos dados e materiais foram disponibilizados publicamente por meio da plataforma Zenodo e podem ser acessados em: Flávia Furtado Pessoa de Mendonça, Henrique Castro Martins, \& Paulo Renato Soares Terra. (2019). Capital Structure and Governance Mechanisms External to the Firm: A Cross-Country Analysis (Version V.1). http://doi.org/10.5281/zenodo.3478652

\section{Agradecimentos}

Os autores agradecem à equipe de editores da RAC - Revista de Administração Contemporânea e aos revisores anônimos por seus comentários e sugestões, que melhoraram significativamente essa pesquisa. 